\title{
Decreased Lung Function Associated With Occupational Exposure to Epichlorohydrin and the Modification Effects of Glutathione S-Transferase Polymorphisms
}

\author{
Jiin-Chyuan Luo, MD, DrPH \\ Tsun-Jen Cheng, MD, ScD \\ Hsen-Wen Kuo, PhD \\ Ming J. W. Chang, PhD
}

Epichlorohydrin (1-chloro-2,3,-epoxypropane; ECH) is a strong irritant of the eyes, respiratory tract, and skin. Because the toxic effect of various chemicals can be modified by metabolic traits, in this study, we also investigated the influence of the glutathione S-transferase (GSTM1) and (GSTT1) genes on the toxic effect of ECH. In the GSTM1 null genotype workers, there is a dose-response of lung function tests $\left(F E V_{1}, F E V_{1} / F V C, M M E F\right)$ for ECH exposure, but not in the GSTM1 non-null genotype workers. The ECH exposure was found to be significantly associated with a decreased $F E V_{1}$ value $(\mathrm{P}=0.09)$ and a decreased MMEF value $(\mathrm{P}=0.053)$ after adjusting for other factors. The GSTM1 null genotype was found to be significantly associated with a decreased $F E V_{1}$ value $(\mathrm{P}=0.038)$, decreased $F E V_{1} / F V C$ value $(\mathrm{P}=$ 0.056), and decreased MMEF value $(\mathrm{P}=0.012)$ after adjusting for other factors. This study indicates that obstructive lung abnormalities and small airway lung damage are associated with ECH exposure, and ECH workers with GSTM1 null-type are also associated with increased respiratory damage. (J Occup Environ Med. 2004;46:280-286)

From the Departments of Public Health (Drs Luo and Chang) and Family Medicine (Dr Luo), Chang Gung Medical College, Taoyuan, Taiwan, R.O.C; the Graduate Institute of Occupational Medicine and Industrial Hygiene (Dr Cheng, Dr Kuo), National Taiwan University, Taipei, Taiwan, R.O.C.

Address correspondence to: Jiin-Chyuan Luo, MD, DrPH Department of Public Health, Chang Gung Medical College, 259 Wenhua 1st Road, Kweishan, Taoyuan, 333 Taiwan, R.O.C.; E-mail address: luo5485@ms29.hinet.net.

Copyright $($ by American College of Occupational and Environmental Medicine

DOI: 10.1097/01.jom.0000116807.73005.97 pichlorohydrin (1-chloro-2,3,-epoxypropane) is a colorless liquid used for the manufacture of epoxy resins, surface active agents, adhesives, paints, varnishes, insecticides, and other agricultural chemicals. Absorption through inhalation and skin is of practical importance. $\mathrm{ECH}$ is a strong irritant of the eyes, respiratory tract, and skin. Eye and skin irritation/sensitization was observed in laboratory animals. ${ }^{1}$ Repeated or prolonged exposure can also cause lung, liver, and kidney damage in experimental animals. ${ }^{1}$ According to one industrial report, eye and nasal burning results from $20 \mathrm{ppm} \mathrm{ECH}$ exposure; lung edema and renal lesions could result from exposures greater than 100 ppm; and liver damage could occur after exposure to very high concentration levels. ${ }^{2}$ Occasional cases of skin irritation or sensitization have been reported in the workplace. ${ }^{3-5}$ However, human epidemiologic studies have not provided definitive evidence of an association between occupational $\mathrm{ECH}$ exposure and an increased incidence of organ injury or disease. ${ }^{1}$

Recent studies have indicated that metabolic traits might modulate the toxic effects of various chemicals. Genetic polymorphisms have been detected in a variety of enzymes involved in the metabolism of exogenous chemicals and have been associated with varying degrees of environmental disease causation. Animal studies have shown that 


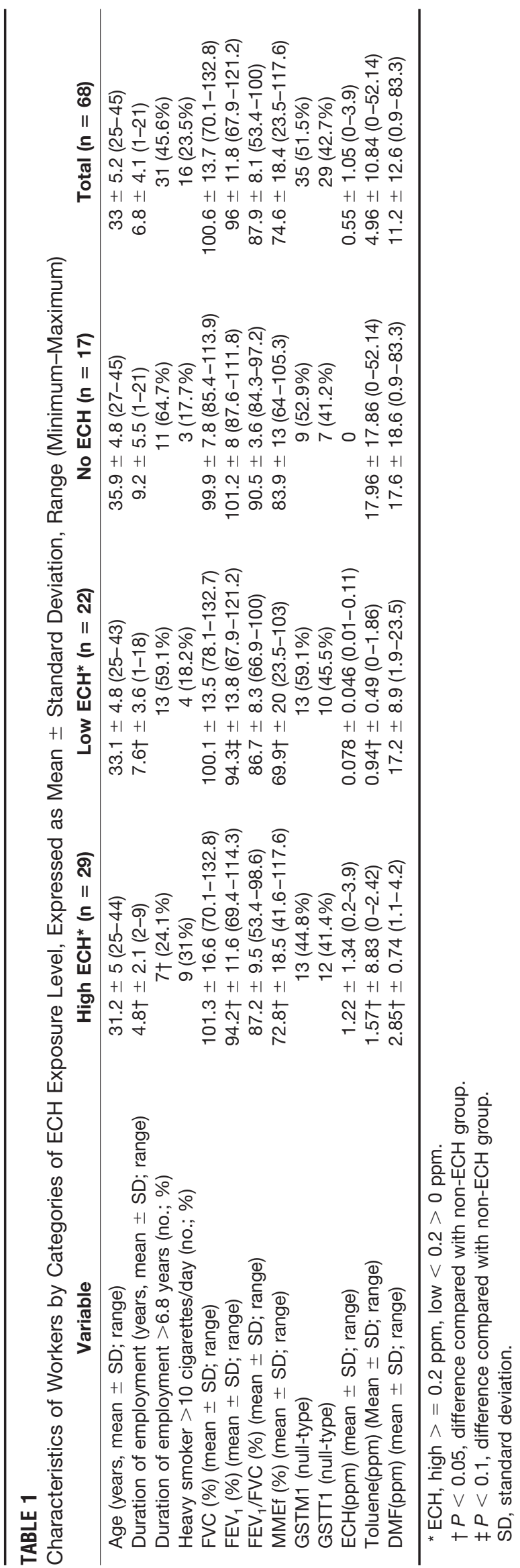

ECH could be conjugated with glutathione to become $\mathrm{N}$-acetyl-S(2,3-dihydroxypropyl) cysteine and N,N'-bis-acetyl-S-S'-(1,3-biscysteinyl) propane-2-ol. ${ }^{6}$ Epoxides have been reported to be substrates for glutathione S-transferase, ${ }^{7}$ and GSTM1 and GSTT1 polymorphisms have been reported. ${ }^{8}$ Our previous report showed GSTM1 null genotype was found to be associated with increased SCE frequency in ECH-exposed workers. ${ }^{9}$ Thus, ECH workers with susceptible GSTM1 could be associated with increased respiratory function damage. Another previous study also suggested that obstructive lung abnormalities and small airway lung damage were associated with ECH exposure. ${ }^{10}$ The study also suggested that exposure to very low concentrations $(<0.2 \mathrm{ppm})$ caused significant higher prevalence of respiratory tract irritation symptoms. ${ }^{10}$ In this study, we furthermore investigated the modulatory effects of GSTM1 on ECH-induced respiratory damage.

\section{Materials and Methods}

In October 1996, a total of 68 males from 3 workstations of a resin synthesis factory where epoxy resin (workstation I), printed circuit (PC) boards (workstation II), and artificial leather (workstation III) were manufactured were recruited for this study. Personal and area air sampling was performed to determine $\mathrm{ECH}$, dimethylformamide (DMF), and toluene concentrations of workers, and details have been published elsewhere. ${ }^{11}$ Briefly, a total of 21 area sampling points were selected throughout the plant based on proximity to sources of solvent emissions. Sampling time ranged from 30 to 180 minutes. Forty-five workers were also selected at random for personal sampling.

Most workers engaged in epoxy resin manufacturing were considered to have increased $\mathrm{ECH}$ exposure, most workers in the PC board plant were considered to have both $\mathrm{ECH}$ 
and DMF exposure, and synthetic leather-manufacturing plant workers were considered to have DMF exposure and no ECH exposure. Study subjects were divided into 3 groups according to ECH exposure concentrations (Table 1). The cutoff point for high and low exposure to ECH was defined arbitrarily to be 0.2 ppm. Job descriptions of high ECHexposure workers included ECH unloading, research and development operators, and maintenance in epoxy resin production. Job descriptions of the low ECH-exposure workers included dipping, assembly of PC boards, materials mixing, and quality control in PC board production. Job descriptions of the non-ECH-exposure workers included materials spraying, mixing, maintenance, printing, research and development, and textile preparation in synthetic leather production.

Informed consent was obtained from all subjects. Demographic data, work history, and smoking status were gathered by a standard selfadministered questionnaire. During each pulmonary function test, we obtained raw lung function values and the percentage of predicted values, which were compared with the nomogram for Asian people of the same sex, age, and height.

Ten milliliters of venous blood were drawn into heparinized tubes (Vacutainer) and stored at $4{ }^{\circ} \mathrm{C}$. The whole blood was separated into plasma, buffy coat, and red blood cells by centrifugation within 18 hours of obtaining the blood and then stored in a $-70^{\circ} \mathrm{C}$ freezer. Genome DNA was extracted and purified from buffy coat. The GSTM1 and GSTT1 genotypes were determined by coamplification of both genes ${ }^{12,13}$ with polymerase chain reaction (PCR). Briefly, PCR was performed in a $25-\mu \mathrm{L}$ mixture containing the buffer supplied by Promega (Madison, WI), $250 \mathrm{ng}$ of genomic DNA, Tag DNA polymerase (1U), 4 bases (dNTP), and $200 \mu \mathrm{g}$ of each of the primers. The primers used for the GST M1 gene were 5'-CTGC-
CCTACTTGA- TTGA TGGG-3' and 5 '-CTGGATTGTAGCAGATCATGC- $3^{\prime}$. The primers used for the GSTT1 gene were 5'-TTCCTTACTGGTCCTCACATCT C-3' and 5'TCACC- GGATCATGGCCAGCA$3^{\prime}$. The human B-globin gene (110 bp) was also amplified in each reaction as a positive control to confirm the presence of amplifiable DNA in the samples. The primers used for B-globin were 5'-ACACAACT GT GTTCACTAG- C-3' and 5'CAACTCATCCACGTTCACC- $3^{\prime}$. The amplification was carried out 35 cycles with denaturation at $94^{\circ} \mathrm{C}$ for 1 minute 30 seconds, annealing at $52^{\circ} \mathrm{C}$ for 1 minute, and extension at $65^{\circ} \mathrm{C}$ for 1 minute. The PCR products were then resolved by electrophoresis in $2 \%$ agarose gels, stained with ethidium bromide, and photographed under ultraviolet light. Individuals with one or more GSTM1 alleles had a 273-bp fragment, and individuals with one or more GSTT1 alleles had a 480-bp fragment.

The data from the 68 workers were encoded, entered, and analyzed with the assistance of the Statistical Analysis System (SAS) PC software package $^{14}$ and Database III plus. ${ }^{15}$ We used $t$ test to test the differences among the working sections and controls in means of the percentage of predicted forced vital capacity (FVC) value, the percentage of the predicted forced expiratory volume in 1 second $\left(\mathrm{FEV}_{1}\right)$, forced expiratory volume in 1 second as a percentage of $\mathrm{FVC}\left(\mathrm{FEV}_{1} / \mathrm{FVC}\right)$, and the percentage of the predicted mean midexpiratory flow (MMEF). Multivariate regression analysis was used to control for the effects of potential confounders on the association between exposure groups, GSTM1 status, and lung function tests.

\section{Results}

The basic characteristics of 68 male workers are summarized in Table 1. The average ECH exposure concentration was $1.22 \mathrm{ppm}$ (range, 0.2-3.9 ppm) in the high-exposure group and 0.078 ppm (range, 0.01-
$0.11 \mathrm{ppm}$ ) in the low-exposure group. The non-ECH-exposure workers seemed to be significantly older than the high-exposure workers and also had a significantly longer duration of employment than others. There were significantly lower values for average lung function tests $\left(\mathrm{FEV}_{1}, \mathrm{MMEF}\right)$ in high ECH-exposure workers than in the non-ECHexposure group $\left(\mathrm{FEV}_{1} 94.2 \pm 11.6 \%\right.$ vs. $101.2 \pm 8 \%$; MMEF $72.8 \pm$ $18.5 \%$ vs. $83.9 \pm 13 \%$ ). There were significantly lower values for average lung function tests (MMEF) in low ECH-exposure workers than in the non-ECH-exposure group (MMEF $69.9 \pm 20 \%$ vs. $83.9 \pm$ $13 \%)$. Because lung function tests $\left(\mathrm{FEV}_{1}, \mathrm{FEV}_{1} / \mathrm{FVC}, \mathrm{MMEF}\right)$ were not significantly different between the high and low ECH-exposed groups, data on lung function tests of these 2 groups were combined for further analysis.

The overall prevalences of GSTM1 null genotype and GSTT1 null genotype were $51.5 \%$ and $42.7 \%$, respectively. The characteristics of workers by GSTM1 status and GSTT1 status were shown in Tables 2 and 3. GSTM1 null genotype workers had significantly lower values for average lung function tests $\left(\mathrm{FEV}_{1}, \mathrm{FEV}_{1} / \mathrm{FVC}, \mathrm{MMEF}\right)$ than the GSTM1 non-null genotype workers $\left(\mathrm{FEV}_{1} 92.6 \pm 11.2 \%\right.$ vs. $99.5 \pm$ $11.6 \% ; \mathrm{FEV}_{1} / \mathrm{FVC} 85.9 \pm 9.5 \%$ vs. $89.9 \pm 5.6 \%$, MMEF $69 \pm 18.1 \%$ vs. $80.6 \pm 17.1 \%$ ) (Table 2). GSTM1 non-null genotype workers had significant more heavy smokers than GSTM1 null genotype workers $(P$ $<0.1)$. In the 2 GSTT1 genotype groups, the lung function tests $\left(\mathrm{FEV}_{1}, \mathrm{FEV}_{1} / \mathrm{FVC}, \mathrm{MMEF}\right)$, age, duration of employment, smoking status, and $(\mathrm{ECH}$, toluene, DMF) exposure concentration were not different (Table 3).

The average $\mathrm{FEV}_{1}, \mathrm{FEV}_{1} / \mathrm{FVC}$, and MMEF value stratified by GSTM1 status and categories of ECH exposure are shown in Table 4. Among the ECH-exposure group, GSTM1 null genotype workers had 
TABLE 2

Characteristics of Workers by GSTM1 status, Expressed as Mean \pm Standard Deviation, Range (minimum-maximum)

\begin{tabular}{|c|c|c|}
\hline Variable & GSTM1 (null-type) $(n=35)$ & GSTM1 (non-null type) $(n=33)$ \\
\hline Age (years, mean $\pm \mathrm{SD}$; range) & $32.7 \pm 4.9(25-43)$ & $33.3 \pm 5.5(25-45)$ \\
\hline Duration of employment (years, mean $\pm \mathrm{SD}$; range) & $6.8 \pm 4.1(1-21)$ & $6.8 \pm 4.1(1-19)$ \\
\hline Duration of employment $>6.8$ years, (no., \%) & $13(37.1 \%)$ & $10(30.3 \%)$ \\
\hline FVC $(\%)($ mean \pm SD; range) & $99.8 \pm 14.6(70.1-132.8)$ & $101.3 \pm 12.9(74.5-132.7)$ \\
\hline $\mathrm{FEV}_{1}(\%)($ mean $\pm \mathrm{SD} ;$ range $)$ & $92.6^{*} \pm 11.2(67.9-111.3)$ & $9.5 \pm 11.6(71.3-121.2)$ \\
\hline $\mathrm{FEV}_{1} / \mathrm{FVC}(\%)$ (mean $\pm \mathrm{SD}$; range) & $85.9^{\star} \pm 9.5(53.4-97.2)$ & $89.9 \pm 5.6(73.6-100)$ \\
\hline Toluene $(\mathrm{ppm})$ (mean $\pm \mathrm{SD}$; range) & $3.5 \pm 8.3(0-32.8)$ & $6.5 \pm 13(0-52.1)$ \\
\hline $\mathrm{DMF}(\mathrm{ppm})($ mean $\pm \mathrm{SD}$; range) & $10.4 \pm 9(0.9-24.8)$ & $12.1 \pm 15.7(1.1-83.3)$ \\
\hline
\end{tabular}

${ }^{*} P<0.05$, difference compared to GSTM1 (non-null) group.

† $P<0.1$, difference compared to GSTM1 (non-null) group.

$\mathrm{SD}$, standard deviation.

TABLE 3

Characteristics of workers by GSTT1 status, expressed as mean \pm standard deviation, range (minimum-maximum)

\begin{tabular}{|c|c|c|}
\hline Variable & GSTT1 (null type) $(n=29)$ & GSTT1 (non-null type) $(n=39)$ \\
\hline Age (years, mean \pm SD range) & $32.3 \pm 4.4(25-39)$ & $33.5 \pm 5.7(25-45)$ \\
\hline Duration of employment (years, mean $\pm \mathrm{SD}$; range) & $6.2 \pm 3.1(1-14)$ & $7.3 \pm 4.6(1-21)$ \\
\hline Duration of employment $>6.8$ years (no., \%) & $9(31 \%)$ & $14(35.9 \%)$ \\
\hline FVC (\%) (mean \pm SD; range) & $102.8 \pm 12.1(79.1-132.7)$ & $98.9 \pm 14.7(70.1-133)$ \\
\hline $\mathrm{FEV}_{1}(\%)($ mean $\pm \mathrm{SD}$; range) & $96.9 \pm 12.6(67.9-121.2)$ & $95.4 \pm 11.4(69.4-111.8)$ \\
\hline $\mathrm{FEV}_{1} / \mathrm{FVC}(\%)$ (mean \pm SD; range) & $86.8 \pm 7(66.9-96.3)$ & $88.7 \pm 8.7(53.4-100)$ \\
\hline Toluene $(\mathrm{ppm})$ (mean \pm SD; range) & $4.1 \pm 9(0-32.8)$ & $5.6 \pm 12.1(0-52.1)$ \\
\hline $\mathrm{DMF}(\mathrm{ppm})($ mean $\pm \mathrm{SD}$; range) & $12.0 \pm 16(1.1-83.3)$ & $10.6 \pm 9.6(0.9-24.8)$ \\
\hline
\end{tabular}

SD, standard deviation.

significantly lower values for average lung function tests $\left(\mathrm{FEV}_{1}, \mathrm{FEV}_{1} /\right.$ FVC, MMEF) than the GSTM1 nonnull genotype workers. Among the non-ECH-exposure group, the average lung function tests $\left(\mathrm{FEV}_{1}, \mathrm{FEV}_{1} /\right.$ FVC, MMEF) were not different in the 2 GSTM1 genotype workers. Among the GSTM1 null genotype group, the ECH-exposed workers had significantly lower values for average lung function tests $\left(\mathrm{FEV}_{1}\right.$, $\mathrm{FEV}_{1} / \mathrm{FVC}$, MMEF) than the nonECH-exposed workers. Among the GSTM1 non-null genotype group, the average lung function tests $\left(\mathrm{FEV}_{1}, \mathrm{FEV}_{1} / \mathrm{FVC}, \mathrm{MMEF}\right)$ were not different in the $2 \mathrm{ECH}$-exposed workers.

Multiple regression analysis was performed to analyze the relationships of lung function tests with po- tential explanatory indicators, including duration of employment, smoking, ECH exposure, DMF exposure, Toluene exposure, and the inherited metabolic traits conferred by GSTM1 genes (Table 5). ECH exposure was found to be significantly associated with decreased average MMEF value $(P=0.053)$ and decreased average $\mathrm{FEV}_{1}$ value $(P=$ $0.09)$ after adjusting for other factors. The GSTM1 null genotype was found to be significantly associated with a decreased $\mathrm{FEV}_{1}$ value $(P=$ 0.038 ), decreased $\mathrm{FEV}_{1} / \mathrm{FVC}$ value $(P=0.056)$, and decreased MMEF value $(P=0.012)$ after adjusting for other factors.

\section{Discussion}

Our study showed that ECH exposure was found to be significantly associated with decreased average MMEF value and decreased average $\mathrm{FEV}_{1}$ value, suggesting that obstructive lung function abnormalities and small airway lung damage were associated with ECH exposure.

The mammalian GST supergene family is composed of $\alpha, \pi, \mu$, and $\theta$ and catalyzes the conjugation of GSH with electrophilic substrates. Some individuals carry a large deletion (null genotype) in glutathione S-transferase $\mu$ (GSTM1) gene and glutathione S-transferase $\theta$ (GSTT1) gene. Individuals with the GSTM1 or GSTT1 null genotype are expected to detoxify environmental toxicants less effectively, thus increasing the concentrations of toxic metabolites in plasma and affecting the clinical outcomes. An individual without an intact GSTM1 could have a higher 
TABLE 4

The average $F E V_{1} / F V C, F E V_{1}$, and MMEF value by GSTM1 status, and categories of $\mathrm{ECH}$ exposure, expressed as mean \pm standard deviation, range (minimum-maximum)

\section{ECH group}

GSTM1 (null)

( $n=26)$

GSTM1 (non-null)

( $n=25)$

\begin{tabular}{|c|c|}
\hline $\mathrm{FEV}_{1}(\%)$ (mean $\pm \mathrm{SD}$; range) & $90.5^{\star} \S \pm 11.5(67.9-111.3)$ \\
\hline $\mathrm{FEV}_{1} / \mathrm{FVC}(\%)$ (mean $\pm \mathrm{SD}$; range) & $84.1^{*} \pm 10.1(53.4-95.1)$ \\
\hline MMEF (\%) (mean \pm SD; range) & $64.8^{\star} \pm 17.6(23.5-96.5)$ \\
\hline Non-ECH group & GSTM1 (null) (n = 9) \\
\hline $\mathrm{FEV}_{1}(\%)($ mean $\pm \mathrm{SD}$; range) & $98.8 \pm 8(87.6-110.3)$ \\
\hline $\mathrm{FEV}_{1} / \mathrm{FVC}(\%)$ (mean $\pm \mathrm{SD}$; range) & $91.1 \pm 4.4(84.3-97.2)$ \\
\hline MMEF (\%) (mean \pm SD; range) & $81.2 \pm 13.7(64-98.2)$ \\
\hline
\end{tabular}

\section{TABLE 5}

Multivariate regression analyses between pulmonary function tests and GSTM1 status, ECH exposure categories and related indicators

\begin{tabular}{|c|c|c|c|}
\hline & MMEF & FEV $_{1}$ & FEV $_{1} /$ FVC \\
\hline \multicolumn{4}{|l|}{ Intercept } \\
\hline Para $\mathrm{E} \pm \mathrm{SE}^{*}$ & $90.8 \pm 7.2$ & $103.1 \pm 4.7$ & $91.9 \pm 3.3$ \\
\hline$P$ value & $(0.0001)$ & $(0.001)$ & $(0.0001)$ \\
\hline \multicolumn{4}{|l|}{ Duration } \\
\hline \multicolumn{4}{|l|}{$1(>6.8)$} \\
\hline \multicolumn{4}{|l|}{$0(<6.8)$} \\
\hline Para $E \pm S E$ & $-4.74 \pm 4.8$ & $0.90 \pm 3.1$ & $-0.31 \pm 2.23$ \\
\hline$P$ value & $(0.33)$ & $(0.78)$ & $(0.89)$ \\
\hline \multicolumn{4}{|l|}{ Heavy smoker } \\
\hline \multicolumn{4}{|l|}{1 (yes) } \\
\hline \multicolumn{4}{|l|}{0 (no) } \\
\hline Para $\mathrm{E} \pm \mathrm{SE}$ & $-1.54 \pm 5.1$ & $5.07 \pm 3.31$ & $0.32 \pm 2.4$ \\
\hline$P$ value & $(0.76)$ & $(0.13)$ & $(0.89)$ \\
\hline \multicolumn{4}{|l|}{ GSTM1 } \\
\hline \multicolumn{4}{|l|}{1 (Null) } \\
\hline \multicolumn{4}{|l|}{0 (non-null) } \\
\hline Para $\mathrm{E} \pm \mathrm{SE}$ & $-11.3 \pm 4.4$ & $-6.04 \pm 2.85$ & $-3.95 \pm 2.03$ \\
\hline$P$ value & $(0.012)$ & $(0.038)$ & $(0.056)$ \\
\hline \multicolumn{4}{|c|}{ Exposure categories } \\
\hline \multicolumn{4}{|c|}{$1(\mathrm{ECH})$} \\
\hline \multicolumn{4}{|l|}{0 (Non-ECH) } \\
\hline Para $\mathrm{E} \pm \mathrm{SE}$ & $-12.1 \pm 6.1$ & $-6.88 \pm 4.0$ & $-3.46 \pm 2.85$ \\
\hline$P$ value & $(0.053)$ & $(0.09)$ & $(0.23)$ \\
\hline \multicolumn{4}{|l|}{ DMF } \\
\hline Para $\mathrm{E} \pm \mathrm{SE}$ & $-0.0004 \pm 0.2$ & $-0.05 \pm 0.13$ & $0.066 \pm 0.09$ \\
\hline$P$ value & $(0.99)$ & $(0.69)$ & $(0.47)$ \\
\hline \multicolumn{4}{|l|}{ Toluene } \\
\hline Para $\mathrm{E} \pm \mathrm{SE}$ & $0.13 \pm 0.26$ & $0.045 \pm 0.17$ & $-0.022 \pm 0.12$ \\
\hline$P$ value & $(0.62)$ & $(0.8)$ & $(0.86)$ \\
\hline
\end{tabular}

* Para $\mathrm{E} \pm \mathrm{SE}$ : parameter estimate \pm standard error.

risk of developing cancer or cytogenetic damage. ${ }^{16-18}$ Adverse effects of maternal exposure to environmental tobacco smoke on neonatal birth weight could be modified by the maternal metabolic genotypes, GSTM1 and GSTT1 $1{ }^{19}$ Our previous report showed that GSTM1 null genotype was associated with increased SCE frequency in ECH-exposed workers. ${ }^{9}$ This study suggests that ECH workers with susceptible genotypes (GST M1 null-type) have increased respiratory damage, including small airways and obstructive lung function. The GSTM1 null genotype was significantly associated with decreased average MMEF value, decreased average $\mathrm{FEV}_{1}$ value, and decreased average $\mathrm{FEV}_{1} /$ FVC value. In contrast, GSTT1 genotypes were not associated with lung function tests. Many chemicals have been found to be substrates for GSTT1, including ethylene oxide, dihaloalkalane, and diepoxybutane. $^{20-22}$ It is not clear if ECH is metabolized by GSTT1.

Small airways under $2 \mathrm{~mm}$ in diameter are the primary site of deposition of poorly soluble inhaled toxins and can be affected earliest and most severely. MMEF is a simple, sensitive, and early indicator of obstruction in smaller airways ${ }^{23,24}$ Methacholine inhalation provocation tests are noted to be helpful in evaluating an asymptomatic individual worker with suspected occupational asthma or identifying workers with already hyperreactive airways who might be at greater risk for disease $^{25-28}$ Seventeen of 51 (33.3\%) ECH-exposed workers had obstructive $\left(\mathrm{FEV}_{1}<80 \%\right.$ or $\mathrm{FEV}_{1} / \mathrm{FVC}$ $<75 \%$ ) or small airway lung lesions (MMEF $<60 \%$ ), 5 of them received provocation tests, and 2 (40\%) workers proved to have a hypersensitive airway. One of them is a 33-year-old male maintenance worker with 5 years on his job and $1.1 \mathrm{ppm} \mathrm{ECH}$ exposure. He complained of cough with phlegm, chest tightness, wheezing, and dyspnea for at least the past 3 months. His obstructive lung abnormalities returned to normal 5 months later $\left(\mathrm{FEV}_{1} / \mathrm{FVC} 53.4 \% \rightarrow\right.$ $86.5 \% \mathrm{FEV}_{1} 69.4 \%->72.6 \%$, MMEF $50.7 \% \rightarrow 64 \%$ ) after medical treatment and by avoiding unnecessary exposure through adequate personal respiratory protection and proper engineering controls in the plant. Another hyperactive airway worker with $0.2 \mathrm{ppm} \mathrm{ECH}$ exposure 
also had better lung function (MMEF $53.5 \%->65 \%$ ) after 5 months intervention. During the 5 months of follow up, the lung function of 2 of 3 negative provocation workers also had recovered for the same reasons. These results indicate that $\mathrm{ECH}$ might cause reversible obstructive lung abnormalities through airway irritation and inflammation and also might cause hyperactive airways.

Respiratory tract irritants represent a diverse spectrum of compounds, gases, and chemicals that, when inhaled, result in irritation to mucous membranes manifested as nonspecific inflammation. The water solubility and concentration of the irritants determine the site of injury. Extremely water-soluble compounds such as ammonia cause injury in the upper airway, whereas insoluble gases such as the nitrogen oxides cause peripheral airway and alveolar injury. ECH is a less soluble gas with a $6.48 \%$ water solubility, which might explain its effect on the lower respiratory tract and not on the upper airway.

The precise mechanism of ECHinduced airway abnormalities is still unclear. Studies on the other less water-soluble gases such as nitrogen oxides and ozone could shed light on this. Studies in animal models show that nitrogen dioxide exposure could produce morphologic alterations in the terminal and respiratory bronchioles and adjacent alveolar ducts and alveoli. ${ }^{29-34}$ Within the ciliated cells of bronchiolar epithelium, acute exposure results in hypertrophy and hyperplasia of the type 1 cells followed by death and desquamation of these cells and proliferation and replacement by type 2 cells and causes a thickened air-blood barrier. Chronic exposure could result in alterations in lung architecture resembling those of emphysema. ${ }^{35,36}$ Studies of ozone described inflammatory and biochemical changes in the airways after ozone exposure. ${ }^{37-39}$ Ozone-induced airway reactivity to methacholine was associated with polymorphonuclear leukocyte
(PMN) influx into airways with interleukin 8 and changes in cyclooxygenase metabolites of arachidonic acid.

DMF is not noted to cause pulmonary function abnormality and respiratory tract irritation. Workers with toluene exposures between 200 and 800 ppm might have respiratory and ocular irritation. ${ }^{40,41}$ In this study, toluene concentration was not high enough to cause any lung damage, and DMF concentrations should have had no respiratory effect either. Smoking was noted to cause obstructive lung function abnormalities. $^{42-45}$ In this study, there was no significant relationship between small airway abnormalities or obstructive lung abnormalities and smoking status. The crude estimation of smoking status could have contributed to this finding. Further precise delineation of smoking patterns might be able to clarify this effect.

This study is limited by its small sample size and results (with borderline significance and confidence intervals less than 1), which indicate that obstructive lung abnormalities, small airway lung damage are associated with ECH exposure, and $\mathrm{ECH}$ workers with GSTM1 null-type could be associated with increased respiratory damage. The study also indicates that exposure to very low concentrations $(<0.2 \mathrm{ppm})$, which are far below the current OSHA TLV of 2 ppm, can cause small airway lung dysfunction. Further studies are needed to better clarify the nature of the observed association.

\section{Acknowledgments}

The authors thank Dr. Paul Brandt-Rauf for his thoughtful comments. This study was supported by grants from the Chang Gung Medical Center (NSC 85-2331-B-182-106) and the National Science Council in Taiwan (NSC86-2621-B182-002-Z; NSC87-2621B182-002-Z).

\section{References}

1. Gardiner TH, Waechter JM, Stevenson DE. Epichlorohydrin. In: Clayton GD, Clayton FE, eds. Patty's Industrial Hygiene and Toxicology, 4th ed, vol II, part
A. New York: Wiley-Interscience; 1993: 417-422.

2. Criteria for a Recommended Standard, occupational Exposure to Epichlorohydrin. National Institute for Occupational Safety and Health, US Department of Health, Education and Welfare. Washington, DC: US Government Printing Office. DHEW (NIOSH) Pub No 76-206, 1976:1-152.

3. Ippen H, Mathies B. Protracted chemical burns with special regard to skin damage caused by epoxide and propane sultane. Berufsdermatosen. 1970;18:144-165.

4. Beck MH, King CM. Allergic contact dermatitis to epichlorohydrin in a solvent cement. Contact Dermatitis. 1983;9:315.

5. Prens EP, Jong GD, Joost TV. Sensitization to epichlorohydrin and epoxy system components. Contact Dermatitis. 1986; 15:85-90.

6. De Rooij BM, Commendeuer JM, Ramcharan JR, et al. Identification and quantitative determination of 3-chloro-2hydroxypropylmercapturic acid and a-chlorohydrin in urine of rats treated with epichlorohydrin. $J$ Chromatogr $B$ Analyt Technol Biomed Life Sci. 1996; 685:241-250.

7. Ketterer B. Protective role of glutathione and glutathione transferase in mutagenesis and carcinogenesis. Mutat Res. 1988; 202:343-361.

8. Nelson HH, Wiencke JK, Christiani DC, et al. Ethnic differences in the prevalence of the homozygous deleted genotype of glutathione S-transferase theta. Carcinogenesis. 1995;16:1243-1245.

9. Cheng TJ, Hwang SJ, Kuo HW, et al. Exposure to epichlorohydrin and dimethylformamide, glutathione S-transferase and sister chromatid exchange frequencies in peripheral lymphocytes. Arch Toxicol. 1999;73:282-287.

10. Luo JC, Kuo HW, Cheng TJ, et al. Pulmonary function abnormality and respiratory tract irritation symptoms in epichlorohydrin-exposed workers in Taiwan. Am J Ind Med. 2003;43:440-446.

11. Kuo HW, Huang YS, Lo JC, et al. Exposure to solvents in a synthetic leather manufacturing plant. Int Arch Occup Health. 2000;73:275-280.

12. Comstock KE, Sanderson BJS, Claflin G, et al. GST 1 gene deletion determined by polymerase chain reaction. Nucleic Acids Res. 1990;18:3670.

13. Pemble S, Schroeder KR, Spencer SR, et al. Human glutathione S-transferase theta (GSTT1): cDNA cloning and the characterization of a genetic polymorphism. Biochem J. 1994;300:271-276.

14. SAS Statistical Package, version 6. Cary, NC: SAS Institute, Inc; 1990. 
15. Database III plus. Torrance, CA: AshtonTate; 1986.

16. Seidegard J, Pero RW, Miller DG, et al. Glutathione transferase in human leukocytes as a marker for the susceptibility to lung cancer. Carcinogenesis. 1986;7: 751-753.

17. Seidegard J, Pero RW, Markowitz MM, et al. Isoenzyme(s) of glutathione (class $\mathrm{Mu}$ ) transferase in human leukocytes as a marker for the susceptibility to lung cancer: a follow up study. Carcinogenesis. 1990;11:33-36.

18. Wiencke JK, Kelsey KT, Lameia RA, et al. Human glutathione S-transferase deficiency as a marker of susceptibility to epoxide-induced cytogenetic damage. Cancer Res. 1990;50:1585-1590.

19. Hong YC, Lee KH, Son BK, et al. Effects of the GSTM1 and GSTT1 polymorphisms on the relationship between maternal exposure to environmental tobacco smoke and neonatal birth weight. $J O C$ cup Environ Med. 2003;45:492-498.

20. Fost U, Hallier E, Ottenwalder H, et al. Distribution of ethylene oxide in human blood and its implications for biomonitoring. Hum Exp Toxicol. 1991;10:25-31.

21. Their R, Foest U, Deutschmann S, et al. Distribution of methylene chloride in human blood. Arch Toxicol. 1991;14:254258.

22. Wiencke JK, Pemble S, Ketterer B, et al. Gene deletion of glutathione S-transferase theta: correlation with induced genetic damage and potential role in mutagenesis. Cancer Epidemiol Biomarkers Prev. 1995;4:253-259.

23. Rao NM, Patel TS, Raiyani CV. Pulmonary function status of shopkeepers of Ahmedabad exposed to auto exhaust pollutants. Indian J Physiol Pharmacol. 1992;36:60-64.

24. Chiang CH, Hsu K. Residual abnormalities of pulmonary function in asymptomatic young adult asthmatics with childhood-onset asthma. J Asthma. 1997;34: 15-21.
25. Pepys J, Hutchcroft BJ. Bronchial provocation tests in etiologic diagnosis and analysis of asthma. Am Rev Respir Dis. 1975;112:829-859.

26. American Thoracic Society. Guidelines for bronchial inhalation challenges with pharmacological and antigenic agents. ATS News. Spring 1980.

27. Guidelines for the diagnosis and evaluation of occupational immunologic lung disease. J Allergy Clin Immunol. 1989; 84:791-838.

28. Brooks S, Baker DB, Gann PH. Cold air challenge and platinum skin reactivity in platinum refinery workers. Chest. 1990; 97:1401-1407.

29. Hine CH, Rowe VK. Epichlorohydrin. In: Patty FA, ed. Industrial Hygiene and Toxicology, 2nd ed, vol 2. New York: Interscience; 1968:1622-1625.

30. Wexler B. Determination of epichlorohydrin contamination in an industrial facility for the manufacturing of epoxy resins. Mater Plast (Bucharest). 1971;8:322323.

31. Evans MJ, Stephens RJ, Carbral LJ, et al. Cell renewal in the lungs of rats exposed to low levels of $\mathrm{NO}_{2}$. Arch Environ Health. 1972;24:180-188.

32. Evans MJ, Carbral LJ, Stephen RJ, et al. Transformation of alveolar type 2 cells to type 1 cells following exposure to $\mathrm{NO}_{2}$. Exp Mol Pathol. 1975;22:142-150.

33. Rombout PJA, Dormans JAMA, Marra $\mathrm{M}$, et al. Influence of exposure regimen on nitrogen dioxide-induced morphological changes in the rat lung. Environ Res. 1986;41:466-480.

34. Kubota K, Murakami M, Takenaka S, et al. Effects of long-term nitrogen dioxide exposure on rat lung: morphological observations. Environ Health Perspect. 1987;73:157-169.

35. Haydon GB, Freeman G, Furiosi NJ. Covert pathogenesis of $\mathrm{NO}_{2}$-induced emphysema in the rat. Arch Environ Health. 1965;11:776-783.

36. Glasgow JE, Pietra GG, Abrams WR, et al. Neutrophil recruitment and degranulation during induction of emphysema in the rats by nitrogen dioxide. Am Rev Respir Dis. 1987;135:1129-1136.

37. Sletzer J, Bigby BG, Stulbarg M, et al. $\mathrm{O}_{3}$-induced change in bronchial reactivity to methacholine and airway inflammation in humans. J Appl Physiol. 1986; 60:1321-1326.

38. Koren HS, Devlin RB, Graham D. Ozone-induced inflammation in the lower airways of human subjects. Am Rev Respir Dis. 1989;139:407-415.

39. Chang MM, Wu R, Plopper CG, et al. IL- 8 is one of the major chemokines produced by monkey airway epithelium after ozone-induced injury. Am J Physiol. 1998;275:L524-532.

40. Carlsson A. Exposure to toluene uptake, distribution and elimination in man. $\mathrm{Br} J$ Work Environ Health. 1982;8:43-55.

41. Tahti H, Karkkainen S, Pyykko K. Chronic occupational exposure to toluene. Int Arch Occup Environ Health. 1981;48:61-69.

42. Burrows B, Knudson RJ, Cline MG. Quantitative relationships between cigarette smoking and ventilatory function. Am Rev Respir Dis. 1977;115:195-205.

43. Dockery DW, Speizer FE, Ferris BG Jr, et al. Cumulative and reversible effects of lifetime smoking on simple tests of lung function in adults. Am Rev Respir Dis. 1988;137:286-292.

44. Senior RM, Shapiro SD. Chronic obstructive pulmonary disease: epidemiology, pathophysiology, and pathogenesis. In: Fishman AP, Elias JA, Fishman JA, eds. Fishman's Pulmonary Diseases and Disorders, ed 3. New York: McGrawHill Co, Inc; 1998;680.

45. The Health Consequences of Smoking: Chronic Obstructive Lung Disease. A report of the Surgeon General. Washington, DC: US Department of Health and Human Services, Public Health Service, Office on Smoking and Health, DHHS Publication No. (PHS); 1984:84-50205. 